\title{
PERFORMANCE OF MAGNESIUM HYDROXIDE FLUORIDES AS HETEROGENEOUS ACID CATALYST FOR BIODIESEL PRODUCTION
}

\author{
S. Indrayanah ${ }^{1}$, A. Rosyidah ${ }^{1}$, H. Setyawati ${ }^{2}$ and I.K. Murwani ${ }^{1 *}$ \\ ${ }^{1}$ Jurusan Kimia, Institut Teknologi Sepuluh Nopember, \\ Kampus ITS Sukolilo-Surabaya 60111, Indonesia \\ ${ }^{2}$ Jurusan Kimia, Universitas Airlangga, \\ Kampus UNAIR JL. Airlangga 4-6 Surabaya 40132, Indonesia. \\ *E-mail : irmina@chem.its.ac.id
}

\begin{abstract}
The magnesium hydroxide fluorides, $\mathrm{MgF}_{\mathrm{x}}(\mathrm{OH})_{2-\mathrm{x}}$ with different aging temperatures have been synthesized by the sol-gel method. The resulting materials were characterized by various techniques such as XRD, FT-IR, TG/DTG, $\mathrm{N}_{2}$ adsorption-desorption, pyridine FT-IR and SEM, respectively. The catalytic evaluation of samples was investigated in the simultaneous transesterification and esterification between waste cooking oil (WCO) containing different \%FFA and methanol to yield biodiesel. The performance of the catalyst, especially $\operatorname{MgF}_{\mathrm{x}}(\mathrm{OH})_{2-\mathrm{x}}$ aged at room temperature (RT) showed higher biodiesel yield compared to $\mathrm{MgF}_{\mathrm{x}}(\mathrm{OH})_{2-\mathrm{x}}$ with increasing of aging temperature. The higher catalytic activity could be attributed to Brønsted acid site, pore diameter size and volume of the materials. Moreover, the yield of biodiesel was not correlated with the surface area of $\mathrm{MgF}_{\mathrm{x}}(\mathrm{OH})_{2-\mathrm{x}}$. The reusability or lifetime of catalyst decreased after three runs used.
\end{abstract}

Keywords: $\mathrm{MgF}_{\mathrm{x}}(\mathrm{OH})_{2-\mathrm{x}}$, Aging temperature, Heterogeneous acid catalyst, Biodiesel, Waste cooking oil (WCO).

(C) RASĀYAN. All rights reserved

\section{INTRODUCTION}

The biodiesel has been considered as alternative energy source for fossil-based fuel. Compared with fossilderived fuel, biodiesel produced by transesterification of triglycerides from vegetable oils or animal fats with short-chained alcohols showed many advantages such as high biodegradability, non-toxicity and renewability. However, the biodiesel obtained from refined vegetable oils or animal fats was uneconomical and impractical because of high raw materials price. In order to reduce the production cost of biodiesel, it is necessary to develop innovative technology using alternative feedstock. Based on the previous research, one of the most attractive alternative raw materials was low-quality oil including waste cooking oil (WCO) due to less expensive. Moreover, the use of WCO will not only reduce the price of biodiesel production, but it will also convert the wastes into resources ${ }^{1-6}$.

Conventionally, the biodiesel obtained from low-quality feedstocks required two processes of reaction. The esterification of high FFA using homogeneous acid catalysts such as $\mathrm{H}_{2} \mathrm{SO}_{4}, \mathrm{H}_{3} \mathrm{PO}_{4}$ and $\mathrm{HCl}$ was the first step and transesterification reaction of triglycerides in the presence of a base catalysts like $\mathrm{NaOH}$ or $\mathrm{KOH}$ was the last $\operatorname{stage}^{7-8}$. However, the homogeneous catalyst was not used due to requiring other stages and thus it increased operational cost. Moreover, the catalyst generated much wastewater during product washing, not recoverable and corrosive so that creating other problems to the environment. Therefore, the homogeneous catalyst system for the production of biodiesel became unfavorable.

The use of heterogeneous catalyst system could be used as an alternative. There were many studies to yield biodiesel using heterogeneous base catalysts such as $\mathrm{CaO}$ and Dolomite. The processes were cheaper, less corrosive, more environmentally friendly and easily regenerated ${ }^{9-10}$. However, they were not adaptive to free fatty acids (FFA) and water in low-quality oils. Therefore, the heterogeneous acid catalysts became more popular because they were not sensitive to FFA and water contents ${ }^{11}$. Moreover, they could be used 
as a catalyst in the simultaneous transesterification and esterification for biodiesel production from lowgrade feedstock in a one step. Some of the heterogeneous acid catalysts have been used to produce biodiesel such as $\mathrm{V}_{2} \mathrm{O}_{5}$ phosphate ${ }^{12}$. Amberlyst-15 and Nafion ${ }^{13-14}$, Zirconium based catalysts ${ }^{15-16}$, Heteropoly acids ${ }^{17-}$

${ }^{18}$ and Zeolits ${ }^{19}$. However, these catalysts showed many disadvantages like the inability to high-temperature reaction (Amberlyst-15 and Nafion), mass transfer limitation and deactivation (Zeolites), loss of activity in polar solvents due to high solubility (Heteropoly acids), high cost (Zirconium) and the easy of being deactivated $\left(\mathrm{V}_{2} \mathrm{O}_{5}\right.$ phosphate).

Currently, there is no study on the production of biodiesel from waste cooking oils (WCO) using magnesium hydroxide fluorides, $\operatorname{MgF}_{x}(\mathrm{OH})_{2-\mathrm{x}}$ as a heterogeneous acid catalyst. Therefore, the purpose of this research is to synthesise, characterize and investigate the influence of different aging temperatures of $\mathrm{MgF}_{\mathrm{x}}(\mathrm{OH})_{2-\mathrm{x}}$ in the simultaneous transesterification and esterification between WCO containing different $\%$ FFA and methanol to yield biodiesel. The catalytic activity of the resulting materials, $\operatorname{MgF}_{\mathrm{x}}(\mathrm{OH})_{2-\mathrm{x}}$ with various aging temperatures is monitored in terms of biodiesel yield obtained from the simultaneous reaction of transesterification and esterification between WCO and methanol in a single stage. Moreover, the durability or lifetime of the catalyst is also evaluated in the optimum conditions of reaction with the same catalyst for production of biodiesel.

\section{Chemicals}

\section{EXPERIMENTAL}

Mg turnings (98\%) was obtained from Aldrich Co. Methanol dry, 48 wt.-\% HF, and methanol for HPLC were obtained from Merck Co. Ethanol and acetone were analytically pure or higher and also purchased from Merck Co. The Waste Cooking Oils (WCO) with various \%FFA was obtained from Restoran Sederhana, Surabaya, Indonesia.

\section{Preparation of the Catalyst}

The samples of $\mathrm{MgF}_{\mathrm{x}}(\mathrm{OH})_{2-\mathrm{x}}$ (containing a molar ratio of $\mathrm{Mg}$ alkoxide to $\mathrm{HF}=1: 2$ ) with different aging temperatures were prepared by using $\mathrm{Mg}$ as a precursor and sol-gel technique. $\mathrm{Mg}$ turnings (98\%) (31.68 $\mathrm{mmol}, 0.77 \mathrm{~g}$ ) was reacted with $50 \mathrm{~mL}$ dry methanol for $3 \mathrm{~h}$. Then the amount of $48 \mathrm{wt} . \% \mathrm{HF}$ was added and stirred for $3 \mathrm{~h}$. The sol or gel obtained from the previous step was aged at different temperatures i.e room temperature (RT), 65, 100 and $150{ }^{\circ} \mathrm{C}$ for $12 \mathrm{~h}$. Furthermore, the solvent was removed under vacuum. Finally, the resulting samples were dried under reduced pressure for $5 \mathrm{~h}$ at a temperature of $70{ }^{\circ} \mathrm{C}$.

\section{Characterization of the Catalyst}

The phase and structure of samples prepared by sol-gel method were characterized by X-ray diffraction with $\mathrm{Cu}-\mathrm{K}_{\alpha}$ radiation source at $\lambda=1.54056$ ) and range of $2 \theta$ about $20-80^{\circ}$. Reflections obtained from this characterization were compared with database of JCPDS-PDF. The chemical bonding and subtitues of materials were recorded with a spectrophotometer FT-IR Shimadzu in the range 4000-400 $\mathrm{cm}^{-1}$ using KBR pellets method. The porosity characteristics of the resulting materials were measured by $\mathrm{N}_{2}$ adsorptiondesorption using a micromeritics Quantachrome Instruments. The first, the powder was degassed under reduced pressure at a temperature of $70{ }^{\circ} \mathrm{C}$ and the surface area of solid was determined using BET method. The thermal analysis of the samples was investigated by TG/DTG apparatus, METTLER TOLEDO with a $\mathrm{Pt} / \mathrm{PtRh} 10$ thermocouple in $\mathrm{N}_{2}$ atmosphere. The morphology or topology of the samples was studied using scanning electron microscopy (SEM) (ZEISS EVO MA 10). The surface acidity was determined by FTIRpyridine adsorption method. The pyridine with a purity $\geq 99.5 \%$ was supplied by Aldrich Co. The first, the powder $(15 \mathrm{mg})$ was pressed and activated for $3 \mathrm{~h}$ under vacuum at $70^{\circ} \mathrm{C}$. After heating to a temperature of $150{ }^{\circ} \mathrm{C}$, the probe is injected during 10 minutes. Furthermore, the spectrum of pyridine adsorbed/desorbed samples were recorded with a spectrophotometer FT-IR Shimadzu in the range from 1300 to $1600 \mathrm{~cm}^{-1}$ with an activated sample as a blank.

\section{Catalytic Test}

The catalytic activity of the resulting samples was tested in the simultaneous reaction of transesterification and esterification between waste cooking oils (WCO) and methanol. The reaction of WCO and methanol 
in a single step was carried out in a Teflon-lined $200 \mathrm{~mL}$ autoclave equipped. The first stage, the reactor was charged with $10 \mathrm{~g}$ of $\mathrm{WCO}$ and $48 \mathrm{~mL}$ methanol (corresponding to the molar ratio of WCO and methanol of $1: 30$ ) with $0.5 \mathrm{~g}$ catalyst (5\% of WCO). Then, the mixtures were heated to $150{ }^{\circ} \mathrm{C}$ (oil batch) under constant stirring $(600 \mathrm{rpm})$ for 5 hours. Later, the mixtures were allowed to cool down and the catalyst was separated by centrifugation. The residual methanol was removed with a rotary evaporator and methyl esters, known as biodiesel, was performed with GC chromatography equipped (HP6890) equipped FID detector. Instrument setting: oven (Ramps temperature) $=140{ }^{\circ} \mathrm{C}$, injector temperature $=200{ }^{\circ} \mathrm{C}$ and detector temperature $=250{ }^{\circ} \mathrm{C}$.

In this research, information about the stability or durability of catalyst was very important. Therefore, to investigate the reusability of the catalyst, the simultaneous transesterification and esterification between WCO and methanol were performed with the same catalyst and the reaction conditions (WCO to methanol molar ratio of $1: 30$ at temperature $150{ }^{\circ} \mathrm{C}$ for 5 hours under stirring speed $600 \mathrm{rpm}$ with $5 \mathrm{wt} . \%$ catalyst). After the reaction finished, mixtures were allowed to cool down and the catalyst was separated by centrifugation. Further the catalyst was separated, washed with ethanol, acetone and distilled water to remove the impurities and used for the subsequent runs.

\section{X-ray diffraction (XRD)}

\section{RESULTS AND DISCUSSION}

The sol-gel technique has been used for synthesis of $\mathrm{MgF}_{\mathrm{x}}(\mathrm{OH})_{2-\mathrm{x}}$ with different aging temperatures. In this method, it happens two-step reactions (hydrolysis magnesium as precursor and fluorosis to obtain $\mathrm{Mg}-\mathrm{F}$ bond ${ }^{20}$. The structure and phase of $\mathrm{MgF}_{\mathrm{x}}(\mathrm{OH})_{2-\mathrm{x}}$ with different aging temperatures were characterized by X-ray diffraction. The XRD patterns of $\mathrm{MgF}_{\mathrm{x}}(\mathrm{OH})_{2-\mathrm{x}}$ with different aging temperatures are summarized in Figure-1. The diffractogram patterns of the resulting samples as shown in Figure- 1 shows main peaks at $2 \theta$ $=27.2^{\circ} ; 40.4^{\circ}$; and 53.5 ${ }^{\circ}$. These peaks show characteristic peaks of $\mathrm{MgF}_{2}(\diamond)$, which are indexed to the (110), (111) and (211) planes of rutile structure of pure $\mathrm{MgF}_{\mathrm{x}}(\mathrm{OH})_{2-\mathrm{x}}$ (matched with the standard JCPDS card No. 70-2269), respectively. The X-ray diffraction technique is also used to determine changes in the structure, phase and crystallinity of the modified $\operatorname{MgF}_{\mathrm{x}}(\mathrm{OH})_{2-\mathrm{x}}$ with different aging temperatures. As shown in Figure-1, X-ray diffractogram patterns of $\mathrm{MgF}_{\mathrm{x}}(\mathrm{OH})_{2-\mathrm{x}}$ with different aging temperatures are similar. Based on the results of characterization using X-ray diffraction technique showed that different aging temperatures up to $150^{\circ} \mathrm{C}$ does not change the structure of $\mathrm{MgF}_{\mathrm{x}}(\mathrm{OH})_{2-\mathrm{x}}$.

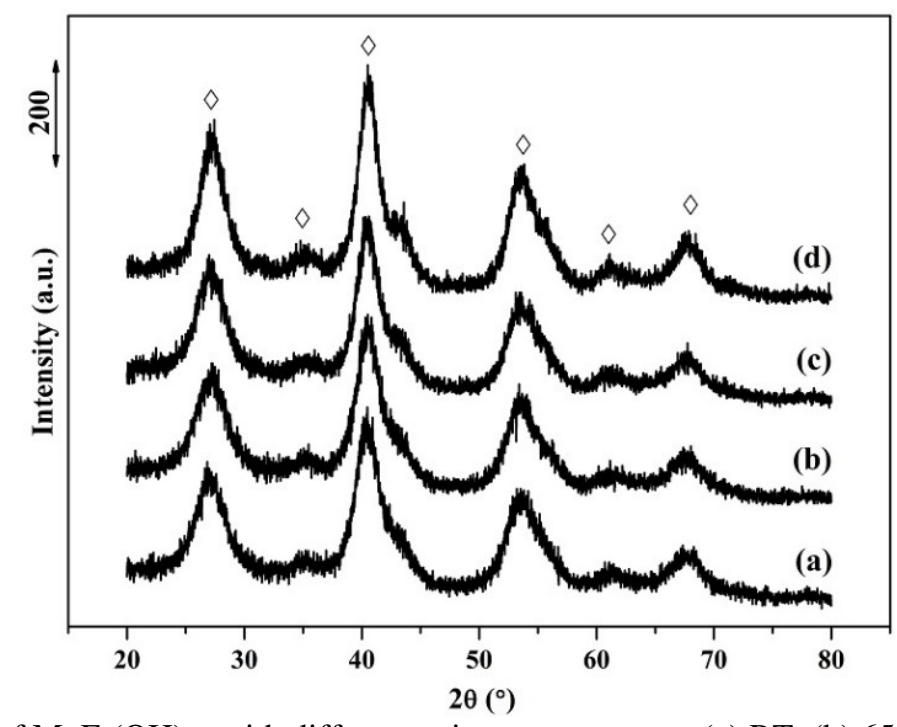

Fig.-1: XRD patterns of $\mathrm{MgF}_{\mathrm{x}}(\mathrm{OH})_{2-\mathrm{x}}$ with different aging temperatures: (a) RT, (b) 65, (c) 100 and (d) $150{ }^{\circ} \mathrm{C}$

\section{Fourier-Transform Infrared Spectroscopy (FT-IR)}

The materials prepared by sol-gel method with different aging temperatures were also characterized by FT- 
RASĀYAN J. Chem.

Vol. 11 | No. 1 |312 - 320 | January - March | 2018

IR spectroscopy. The resulting spectra were interpreted to determine of chemical bonding based on its vibrations. The spectra of $\mathrm{MgF}_{\mathrm{x}}(\mathrm{OH})_{2-\mathrm{x}}$ with different aging temperatures are shown in Figure-2. All samples show broad O-H bands ( $)$ located at $3400-3700 \mathrm{~cm}^{-1}$ that are stretching vibration of water, while the bending vibration of $\mathrm{H}-\mathrm{O}-\mathrm{H}$ and bridged $\mathrm{OH}$ group appear about $1640 \mathrm{~cm}^{-1}(\bullet)$. The infrared spectra of $\mathrm{MgF}_{\mathrm{x}}(\mathrm{OH})_{2-\mathrm{x}}$ with different aging temperatures as presented in the Figure-2 exhibit the same vibration at wavenumber about $490 \mathrm{~cm}^{-1}(\diamond)$ which indicate $v_{\mathrm{Mg}-\mathrm{F}}$ vibration. It is clear that $\mathrm{MgF}_{\mathrm{x}}(\mathrm{OH})_{2-\mathrm{x}}$ which are synthesized by different aging temperatures does not destroy the structure or chemical bonding of $\mathrm{MgF}_{\mathrm{x}}(\mathrm{OH})_{2-\mathrm{x}}$ sample, similar to the XRD result.

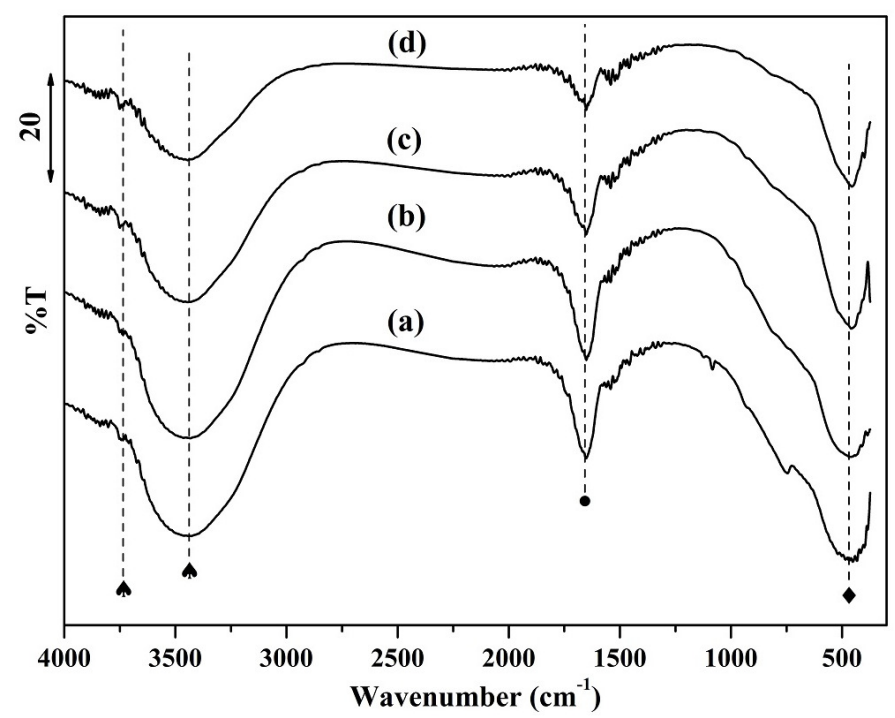

Fig.-2: FTIR spectra of $\mathrm{MgF}_{\mathrm{x}}(\mathrm{OH})_{2-\mathrm{x}}$ with different aging temperatures: (a) RT, (b) 65, (c) 100 and (d) $150{ }^{\circ} \mathrm{C}$

\section{Thermal Analysis}

Thermal analysis of $\mathrm{MgF}_{\mathrm{x}}(\mathrm{OH})_{2-\mathrm{x}}$ with different aging temperatures was carried out to investigate the thermal stability of materials, especially the influence of different aging temperatures. The TG (A)/DTG (B) curves of the samples are shown in the Fig.-3. The curves of all samples as demonstrated in Fig. -3 show very simple one-step destruction phase at a temperature about $80-300^{\circ} \mathrm{C}$ that indicate the release of $\mathrm{MeOH}$ from $\mathrm{Mg}\left(\mathrm{OCH}_{3}\right)_{2} \cdot 2 \mathrm{CH}_{3} \mathrm{OH}$ and loss of the $-\mathrm{OH}$ group on the surface of solids. Further both $\mathrm{TG}(\mathrm{A})$ and DTG (B) curves as shown in Fig.-3, the decomposition and removal of HF which are appeared at a temperature about $600-700^{\circ} \mathrm{C}$ is not observed, indicating that the resulting materials are thermally stable. Based on the result, it can be concluded that $\mathrm{MgF}_{\mathrm{x}}(\mathrm{OH})_{2-\mathrm{x}}$ with different aging temperatures exhibit the same thermal stability.

\section{$\mathbf{N}_{2}$ Adsorption-Desorption Isotherms}

The $\mathrm{N}_{2}$ adsorption-desorption isotherms of $\mathrm{MgF}_{\mathrm{x}}(\mathrm{OH})_{2-\mathrm{x}}$ with various aging temperatures are shown in Fig.4. All samples increase sharply at relatively high pressure, indicating the presence of mesopores. As shown in Figure-4, the adsorption of nitrogen molecules begin to occur in the relative pressure $\mathrm{P} / \mathrm{P}_{0}$ from zero to $<0.1$. All samples start an interaction in the pore when the pressure reaches from the $P / P_{0}=0$ to $P / P_{0}=0.9$, whereas at higher pressure, $\mathrm{P} / \mathrm{P}_{0}<1$ isothermal curve shape are higher. This result indicated that the adsorption occurs at great pressure. At the moment the pressure is lowered to desorption, the isothermal curve shows a hysteresis loop. This is expected because the adsorption is not the same as the desorption. In addition, hysteretic loop also occurs due to capillary condensation of nitrogen molecules. Through capillary condensation can be obtained information about the type of pores. Based on the IUPAC classification, all materials have typical IV Brunauer isotherm with $\mathrm{H} 1$ hysteretic loop, which showed cylindrical pores. Furthermore, the pore diameter size and volume of $\mathrm{MgF}_{\mathrm{x}}(\mathrm{OH})_{2-\mathrm{x}}$ with different aging 
RASĀYAN J. Chem.

Vol. 11 | No. 1 |312 - 320 | January - March | 2018

temperatures decreased from 3.63 to $2.67 \mathrm{~nm}$ and from 0.1 to $0.089 \mathrm{cc} / \mathrm{g}$ after increasing of aging temperatures as shown in Table-1, respectively.
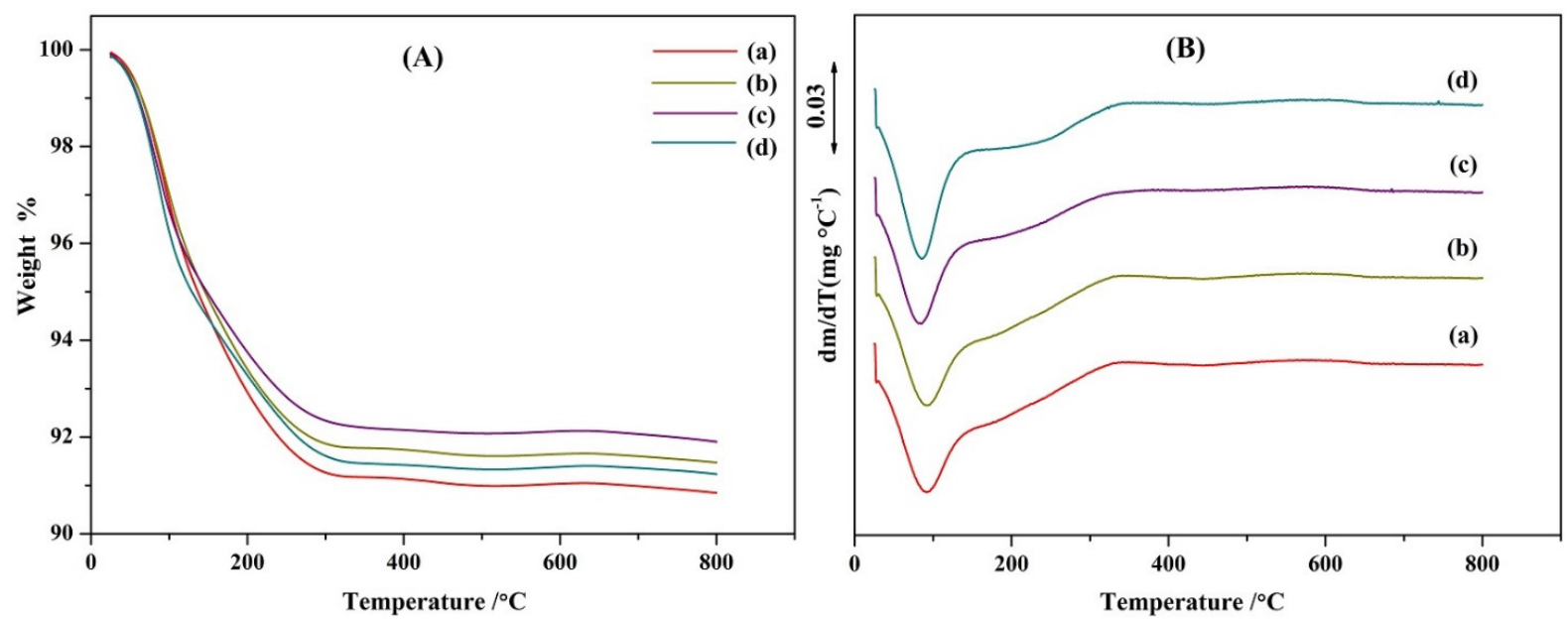

Fig.-3: TG (A) and DTG (B) curves of $\mathrm{MgF}_{\mathrm{x}}(\mathrm{OH})_{2-\mathrm{x}}$ with different aging temperatures: (a) RT, (b) 65, (c) 100 and
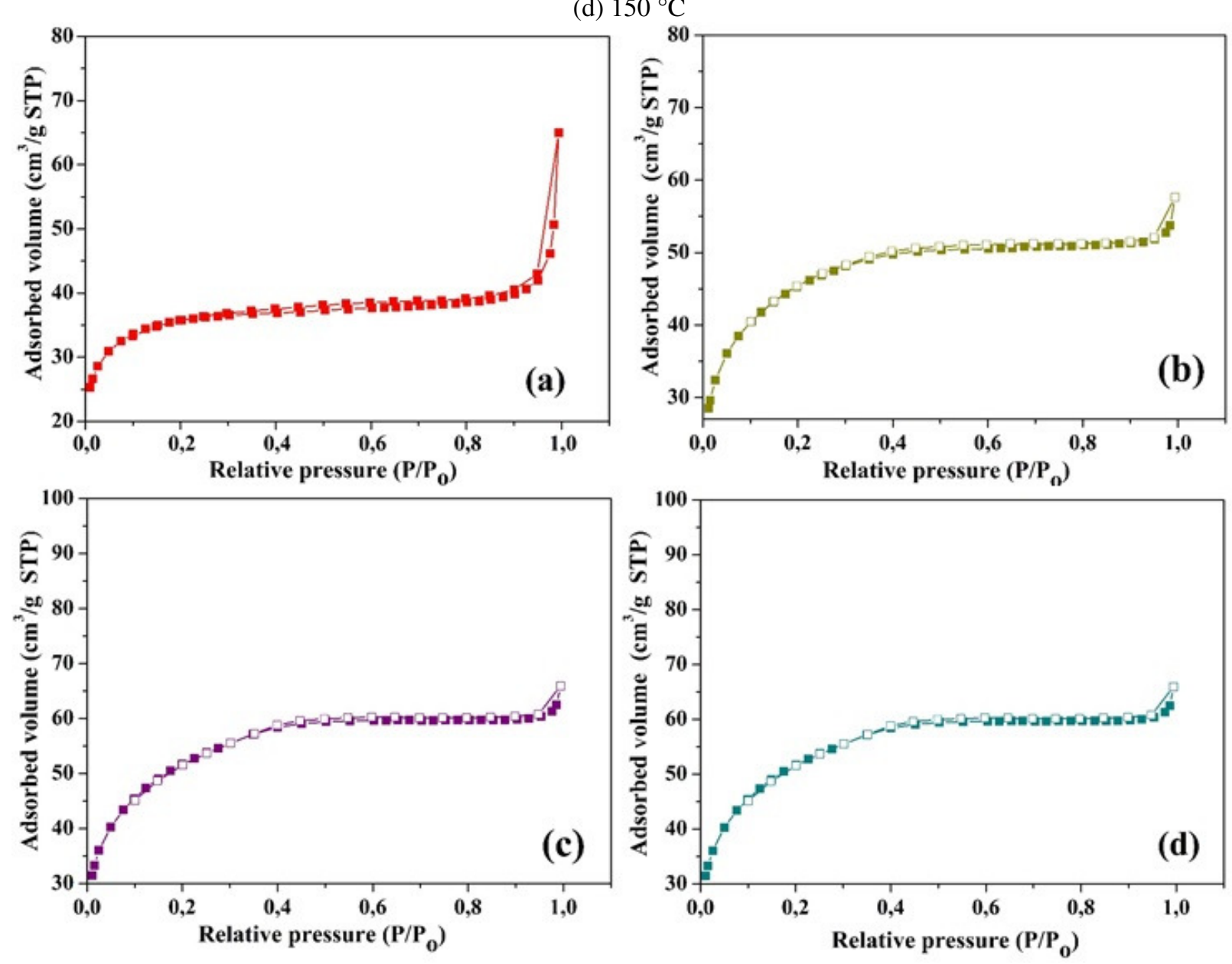

Fig.-4: $\mathrm{N}_{2}$ adsorption-desorption isotherm of of $\mathrm{MgF}_{\mathrm{x}}(\mathrm{OH})_{2-\mathrm{x}}$ with different aging temperatures: (a) RT, (b) 65, (c) 100 and (d) $150{ }^{\circ} \mathrm{C}$

This result indicated that the increase in aging temperature can decrease the average pore size and pore 
RASĀYAN J. Chem.

Vol. 11 | No. 1 |312 - 320 | January - March | 2018

volume of samples. Generally, the specific surface area (BET) of the materials increased with increasing of aging temperatures. Especially for aging temperature of $150{ }^{\circ} \mathrm{C}$, the specific surface area of $\mathrm{MgF}_{\mathrm{x}}(\mathrm{OH})_{2-\mathrm{x}}$ is $171.88\left(\mathrm{~m}^{2} / \mathrm{g}\right)$ as shown in Table-1. This indicated that the increase of aging temperatures in the sol-gel method increase the surface area of $\mathrm{MgF}_{\mathrm{x}}(\mathrm{OH})_{2-\mathrm{x}}$.

Table-1: Physicochemical properties of catalysts

\begin{tabular}{|c|c|c|c|c|c|}
\hline \multirow[t]{2}{*}{ Catalysts } & \multirow[t]{2}{*}{$\mathrm{S}_{\mathrm{BET}}\left(\mathrm{m}^{2} / \mathrm{g}\right)$} & \multirow{2}{*}{$\begin{array}{l}\text { Pore diameter } \\
\text { size }(\mathrm{nm})\end{array}$} & \multirow{2}{*}{$\begin{array}{l}\text { Pore volume } \\
\qquad(\mathrm{nm})\end{array}$} & \multicolumn{2}{|c|}{ Acid sites } \\
\hline & & & & $\begin{array}{c}\text { Lewis } \\
(\mathrm{mmol} / \mathrm{g})\end{array}$ & $\begin{array}{l}\text { Brønsted } \\
(\mathrm{mmol} / \mathrm{g})\end{array}$ \\
\hline $\mathrm{MgF}_{\mathrm{x}}(\mathrm{OH})_{2-\mathrm{x}}(\mathrm{RT})$ & 110.97 & 3.63 & 0.100 & 1.458 & 2.319 \\
\hline $\mathrm{MgF}_{\mathrm{x}}(\mathrm{OH})_{2-\mathrm{x}}\left(65^{\circ} \mathrm{C}\right)$ & 150.55 & 2.82 & 0.107 & 1.549 & 1.723 \\
\hline $\mathrm{MgF}_{\mathrm{x}}(\mathrm{OH})_{2-\mathrm{x}}\left(100^{\circ} \mathrm{C}\right)$ & 148.70 & 2.40 & 0.102 & 1.515 & 0.717 \\
\hline $\mathrm{MgF}_{\mathrm{x}}(\mathrm{OH})_{2-\mathrm{x}}\left(150^{\circ} \mathrm{C}\right)$ & 171.88 & 2.67 & 0.089 & 1.704 & 0.523 \\
\hline
\end{tabular}

\section{Acidity Analysis}

The FTIR spectra with pyridine as probe and the values of Lewis/Brønsted acid sites of the resulting materials, $\mathrm{MgF}_{\mathrm{x}}(\mathrm{OH})_{2-\mathrm{x}}$ are shown in Figure-5 and Table-1. All samples show absorption peaks at 1442$1450 \mathrm{~cm}^{-1}$, indicating the presence of Lewis acid site. In addition, there are peaks at $1540-1550 \mathrm{~cm}^{-1}$, which is characteristic peak of Brønsted acid site. With increase in aging temperatures, the peak of Brønsted acid site decrease. This result indicated that the existence of - $\mathrm{OH}$ group decrease with increasing of aging temperatures. The presence of Lewis and Brønsted acid sites in all samples is magnified with a peak at $1490-1500 \mathrm{~cm}^{-1}$.

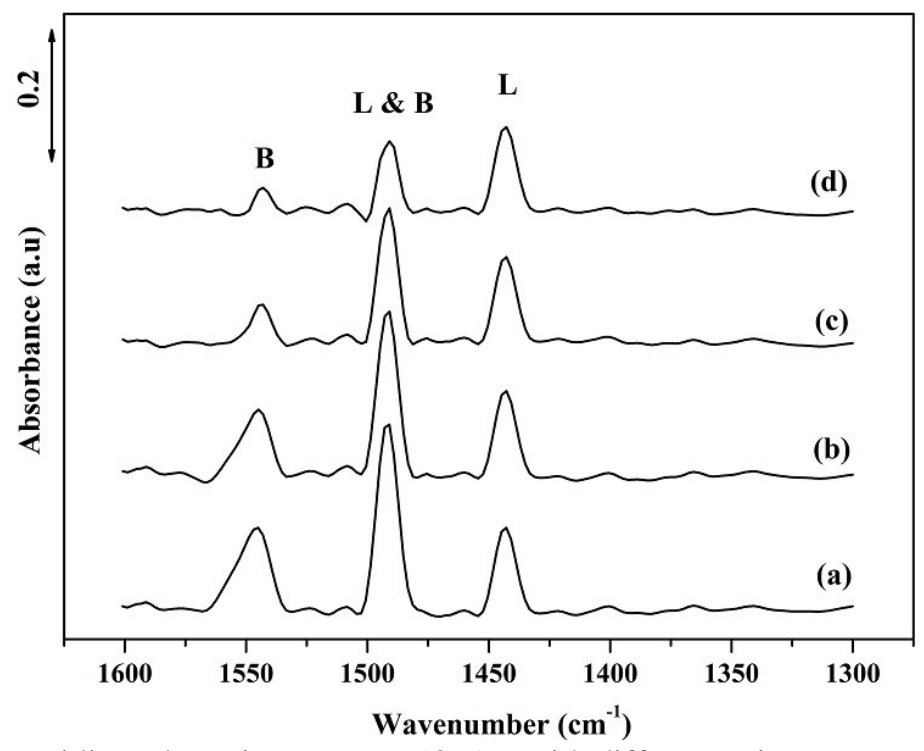

Fig.-5: FTIR spectra for pyridine adsorption on $\mathrm{MgF}_{\mathrm{x}}(\mathrm{OH})_{2-\mathrm{x}}$ with different aging temperatures: (a) RT, (b) 65, (c)

\section{SEM Analysis} 100 and (d) $150{ }^{\circ} \mathrm{C}$

Study of morphology and topography of the samples was determined by SEM. Figure-6 shows the SEM $\mathrm{MgF}_{\mathrm{x}}(\mathrm{OH})_{2-\mathrm{x}}$ with different aging temperatures. As shown in Fig.-6, it can be obtained that the morphology of the samples is dissimilar from that of the sample with an increase in aging temperatures. The particle shapes change also from spired to more spherical and homogeneous with an increase in aging temperatures (Figure-6. b-d). However, the particle size of $\mathrm{MgF}_{\mathrm{x}}(\mathrm{OH})_{2-\mathrm{x}}$ samples are similar, around 0.2-3 $\mu \mathrm{m}$. Moreover, the aglomerate increases with increasing of aging temperatures as shown in Fig.-6 (a-d). 
RASĀYAN J. Chem.

Vol. 11 | No. 1 |312 - 320 | January - March | 2018

\section{Catalytic Activity}

To study the catalytic activity of $\mathrm{MgF}_{\mathrm{x}}(\mathrm{OH})_{2-\mathrm{x}}$ with different aging temperatures as a heterogeneous acid catalyst, the simultaneous reaction of transesterification and esterification between WCO (containing 4, 7, 10, 13 and $17 \%$ FFA) and methanol to yield biodiesel have been used as a probe reaction. The use of methanol in this reaction was because of more reactive and cheaper than other alcohols. The simultaneous transesterification and esterification were evaluated under the optimum conditions of reaction. Based on the previous experiment, the higher yield of biodiesel resulted from the optimum conditions (oil/methanol molar ratio of $1: 30$ at a temperature of reaction about $150{ }^{\circ} \mathrm{C}$ for 5 hours with catalyst/oil mass ratio of $5 \%$ wt. and speed of stirring about $600 \mathrm{rpm}$ ). Therefore, these parameter conditions were used, and the results are summarized in Tabel-2. The data are shown in Table- 2 demonstrate that the biodiesel yield increases from $26.82 \%$ to $38.31,50.14,75.29 \%$ with increasing of the free fatty acids concentration of waste cooking oils, respectively. However, the yield of biodiesel decreases with increasing of FFA up to 17\% (48.45\% biodiesel yield). Based on the results, it is concluded that $\mathrm{MgF}_{\mathrm{x}}(\mathrm{OH})_{2-\mathrm{x}}$ catalyst which aged at room temperature is very adaptive to FFA in waste cooking oil. The presence of acid site, especially Brønsted acid site is believed to improve the biodiesel yield.
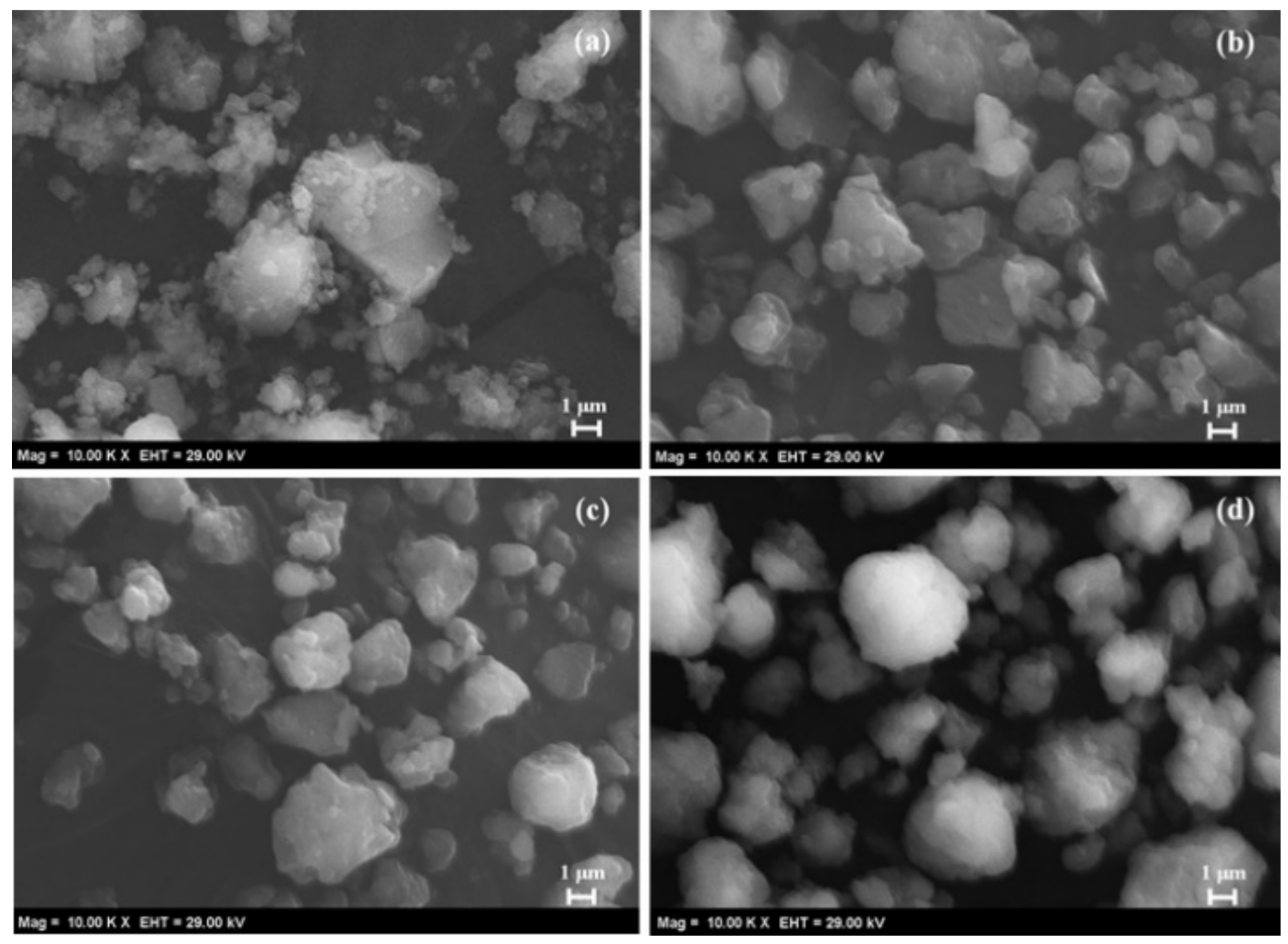

Fig.-6: SEM images of $\mathrm{MgF}_{\mathrm{x}}(\mathrm{OH})_{2-\mathrm{x}}$ with different aging temperatures: (a) RT, (b) 65, (c) 100 and (d) $150{ }^{\circ} \mathrm{C}$

Furthermore, to investigate the effect of different aging temperatures on the $\operatorname{MgF}_{\mathrm{x}}(\mathrm{OH})_{2-\mathrm{x}}$, the reaction of WCO containing 13\% FFA is carried out with optimum reaction condition and the results are presented in Tabel 3. As shown in Tabel 3, the biodiesel yield decreases with increasing of aging temperatures from $75.29 \%$ to $62.11,51.42,23.89 \%$, respectively. The higher activity of $\mathrm{MgF}_{\mathrm{x}}(\mathrm{OH})_{2-\mathrm{x}}$ which aged at room temperature could be correlated with pore diameter size, volume and surface acidity. This result demonstrated that the larger diameter size of pore and volume can absorb more reactants and thus increase its catalytic activity. Moreover, catalyst with a higher total acidity, especially Brønsted acid site is able to capture a large number of FFA in the active site. According to this result, it is clear that the Bronsted acid site is more influence than Lewis acid site in the simultaneous reaction between WCO and methanol in a 
RASĀYAN J. Chem.

Vol. 11 | No. 1 |312 - 320 | January - March | 2018

single step. On the other hand, although the surface area of $\operatorname{MgF}_{x}(\mathrm{OH})_{2-\mathrm{x}}$ with increasing of aging temperature is greater than $\mathrm{MgF}_{\mathrm{x}}(\mathrm{OH})_{2-\mathrm{x}}$ aged at room temperature, but it can not help improve the contact between WCO and methanol. This shows that the catalytic activity of these samples does not correlate to surface area. The combination of pore diameter and the high surface acidity although the lower surface area is able to provide a high biodiesel production.

Table-2: The effects of FFA (\%) on the yield of biodiesel*

\begin{tabular}{l|c|c}
\hline Waste Cooking Oil (WCO) & FFA (\%) & Biodiesel yield (\%) \\
\hline WCO 1 & 4 & 26.82 \\
\hline WCO 2 & 7 & 38.31 \\
\hline WCO 3 & 10 & 50.14 \\
\hline WCO 4 & 13 & 75.29 \\
\hline WCO 5 & 17 & 48.45 \\
\hline
\end{tabular}

*Reaction conditions: $\mathrm{WCO} /$ methanol molar ratio 1:30; reaction temperature $150{ }^{\circ} \mathrm{C}$; reaction time $5 \mathrm{~h}$; catalyst amount 5 wt.\% of $\mathrm{MgF}_{\mathrm{x}}(\mathrm{OH})_{2-\mathrm{x}}(\mathrm{RT})$; and stirring speed $600 \mathrm{rpm}$.

Table-3. The effects of different aging temperatures of $\mathrm{MgF}_{\mathrm{x}}(\mathrm{OH})_{2-\mathrm{x}}$ on the yield of biodiesel*

\begin{tabular}{l|c}
\multicolumn{1}{c|}{ Catalysts } & Biodiesel yield (\%) \\
\hline $\mathrm{MgF}_{\mathrm{x}}(\mathrm{OH})_{2-\mathrm{x}}(\mathrm{RT})$ & 75.29 \\
\hline $\mathrm{MgF}_{\mathrm{x}}(\mathrm{OH})_{2-\mathrm{x}}\left(65^{\circ} \mathrm{C}\right)$ & 62.11 \\
\hline $\mathrm{MgF}_{\mathrm{x}}(\mathrm{OH})_{2-\mathrm{x}}\left(100^{\circ} \mathrm{C}\right)$ & 51.42 \\
\hline $\mathrm{dMgF}_{\mathrm{x}}(\mathrm{OH})_{2-\mathrm{x}}\left(150^{\circ} \mathrm{C}\right)$ & 23.89 \\
\hline
\end{tabular}

* Reaction conditions: $\mathrm{WCO}(13 \% \mathrm{FFA}) /$ methanol molar ratio 1:30; reaction temperature $150{ }^{\circ} \mathrm{C}$; reaction time $5 \mathrm{~h}$; catalyst amount $5 \mathrm{wt} . \%$; and stirring speed $600 \mathrm{rpm}$.

The loss of catalyst activity of materials was an important parameter for the heterogeneous catalytic system in simultaneous transesterification and esterification. The reusability of the catalyst is evaluated by the same reaction conditions and $\mathrm{MgF}_{\mathrm{x}}(\mathrm{OH})_{2-\mathrm{x}}$ aged at room temperature as a catalyst. After each reaction cycles, the used catalyst is recovered by centrifugation and washed with ethanol, acetone and distilled water. The results of the durability of catalysts in simultaneous reactions are displayed in Tabel-4. As summarized in Tabel-4. The yield of biodiesel decreases from $75.29 \%$ to $69.23,51.95 \%$ after being used for three runs, respectively. These results show mass loss during the recovery process and the existence of impurities such as fatty acid and byproducts (glycerol), which can cover the pore of the catalyst.

\begin{tabular}{c|c} 
Table-4: Reusability of $\mathrm{MgF}_{\mathrm{x}}(\mathrm{OH})_{2-\mathrm{x}}(\mathrm{RT})$ catalyst* \\
\hline Cycles & Biodiesel yield $(\%)$ \\
\hline $1^{\text {st }}$ use & 75.29 \\
\hline $2^{\text {nd }}$ use & 69.23 \\
\hline $3^{\text {rd }}$ use & 51.95
\end{tabular}

*Reaction conditions: WCO (13\%FFA)/methanol molar ratio 1:30; reaction temperature $150{ }^{\circ} \mathrm{C}$; reaction time $5 \mathrm{~h}$; catalyst amount 5 wt. $\%$; and stirring speed $600 \mathrm{rpm}$.

\section{CONCLUSION}

The magnesium hydroxide fluorides, $\mathrm{MgF}_{\mathrm{x}}(\mathrm{OH})_{2-\mathrm{x}}$ with different aging temperatures have been successfully obtained from the sol-gel method. Based on the characterization results indicated that all materials showed 
similar structure, thermal stability, and the particle size. However, the pore diameter size, volume and surface acidity, especially Brønsted acid site decreased with increasing of aging temperatures. Catalytic evaluation in the simultaneous transesterification and esterification reaction between WCO and methanol over the resulting materials as heterogeneous acid catalyst indicated that $\operatorname{MgF}_{\mathrm{x}}(\mathrm{OH})_{2-\mathrm{x}}$ aged at room temperature (RT) exhibited higher biodiesel yield compared to $\operatorname{MgF}_{x}(\mathrm{OH})_{2-\mathrm{x}}$ with an increase in aging temperature. The higher activity of catalyst, $\mathrm{MgF}_{\mathrm{x}}(\mathrm{OH})_{2-\mathrm{x}}$ aged at room temperature could be attributed to surface acidity, especially Brønsted acid site, pore size and pore volume. Moreover, the durability of the $\mathrm{MgF}_{\mathrm{x}}(\mathrm{OH})_{2-\mathrm{x}}$ catalyst decreased after three cycles.

\section{ACKNOWLEDGEMENT}

The authors thank Directorate of Higher Education (DIKTI) for granting the scholarship and Graduate Research Programe of LPPM-ITS 2017 for financial support.

\section{REFERENCES}

1. M. Prabhahar, S. Sendilvelan, S. Prakash, M. Saravanakumar, Rasayan J. Chem., 10(4), 1075(2017).

2. S. Sendilvelan and K. Bhaskar, Rasayan J. Chem., 10(3), 1043(2017).

3. A.T. Kiakalaieh, N.A.S. Amin, H. Mazaheri, Appl. Energ. Rev., 104, 683(2013).

4. M. Tariq, S. Ali, N. Khalid, Renew. Sust. Energ. Rev., 16, 6303(2012).

5. A.K. Endalew, Y. Kiros, R. Zanzi, Biomass Bioenergy Rev., 35, 3787(2011).

6. A.P.S. Chouhan and A.K. Sarma, Renew. Sust. Energ. Rev., 15, 4378(2011).

7. M.R. Shahbazi, B. Khoshandam, M. Nasiri, M. Ghazvini, J. Taiwan Inst. Chem. Eng., 43, 504(2012).

8. F. Ferella, G.M. Di Celso, I. De Michelis, V. Stanisci, F. Vegliò, Fuel, 89, 36(2010).

9. V.G. Deshmane and Y.G Adewuyi, Appl. Catal. A: General, 462, 196(2013).

10. R. Olivia, N. Jamarun, S. Arif, Y.A. Sirin, Rasayan J. Chem., 10(1), 160(2017).

11. L. Chen, P. Yin, X. Liu, L. Yang, Z. Yu, X. Guo, X. Xin, Energy, 36, 175(2011).

12. C. Domingues, M.J.V. Correia, R. Carvalho, C. Henriques, J. Bordado, A.P.S Dias, Journal Biotechnology, 164, 433(2013).

13. J. Fu, Z. Li, S. Xing, Z. Wang, C. Miao, P. Lv, Z. Yuan, Fuel, 181, 1058(2016).

14. Y. Ma, Q. Wang, Z. Gao, X. Sun, N. Wang, R. Niu, H. Ma, Renew. Energ., 86, 643(2016).

15. G. Shi, F. Yu, Y. Wang, D. Pan, H. Wang, R. Li, Renew. Energ., 92, 22(2016).

16. Y.M. Sani, P.A. Alaba, A.O.R. Yahya, A.R. AbdulAziza, W.M.A.W. Daud, J. Taiwan Inst. Chem. Eng., 59, 195(2016).

17. Y.Z. Han, L. Hong, X.Q. Wang, J.Z. Liu, J. Jiaoa, M. Luo, Y. J. Fu, Industrial Crops and Products, 89, 332(2016).

18. D.Y. Zhang, M.H. Duan, X.H. Yao, Y.J. Fu, Y.G. Zu, Fuel, 172, 293(2016).

19. Y.M Sani, P.A. Alaba, A.O.R. Yahya, A.R. AbdulAziza, W.M.A.W. Daud, J. Taiwan Inst. Chem. Eng., 60, 247(2016).

20. S. Wuttke, S.M. Coman, J. Kröhnert, F.C. Jentoft, E. Kemnitz, Catal. Today, 152, 2(2010).

[RJC-1904/2017] 